\title{
MODELS OF DISTRIBUTION OF GDP AT THE GLOBAL LEVEL
}

$$
\text { UDC 658.86/.87(100) }
$$

\section{Zoran Tomić*, Ognjen Radović}

\author{
University of Niš, Faculty of Economics, Serbia
}

\begin{abstract}
The problem of distribution has been drawing the attention of researchers for years. In their research they analyze the uniformity of distribution using Pareto model of distribution, the Lorenz curve and the Gini coefficient. Also some authors are testing the applicability of models from statistical physics to the problem of distribution to better describe it. In addition to the analysis of distribution at the level of states and certain groups such as the Forbes list, the problem is spreading to the global level, where we analyze the distribution of GDP as a measure of the wealth of individual countries.

In this paper we analyzed the distribution of GDP of countries applying the Pareto model, Lorenz curve, Gini coefficient and Boltzmann Gibbs distribution from statistical physics. The analysis was done for 2015, while the Gini coefficient analysis was done during the period from 1990 to 2015.
\end{abstract}

Key words: The distribution of wealth, GDP, Pareto distribution, Lorenz curve, Gini coefficient, Boltzmann Gibbs distribution

JEL Classification: D31, R12, C46

\section{INTRODUCTION}

For macroeconomic policy holders, it is important to consider the distribution of wealth. One of the goals that every government wants to achieve is the satisfactory rate of economic growth and development. Besides a large number of indicators, according to Cvetanović (2005) the degree of uniformity of distribution of wealth occupies an important place.

One of the aspects of the impact of policy development is the emergence of imbalances. Economic development is characterized by a marked inequality in time, space and population

Received December 04, 2017 / Revised April 12, 2018 / Accepted April 17, 2018

Corresponding author: Zoran Tomić

${ }^{*}$ PhD student at University of Niš, Faculty of Economics

University of Niš, Faculty of Economics, Trg kralja Aleksandra 11, 18000 Niš, Serbia

E-mail: zoranzoca@gmail.com 
terms. Poor distribution of wealth and income in an economy can have negative effects on economic growth and development. The research by the World Bank in 1996 in the case of East Asia confirms that countries with a more even distribution of wealth and income have higher rates of economic growth. In each East Asian economy that has achieved solid economic growth rates in the period between 1965 and 1990, the inequality in income distribution was reduced (Kitanović \& Golubović, 2006, p 345).

The issue of distribution of wealth and money is topical today. A large number of authors studies the distribution of wealth and money using various models and types of distributions, of which Pareto is the most common. This model was successfully applied in the papers of Levy \& Solomon (1997); Klass et al. (2006); Dunford et al. (2014).

Over time, new models are forming that aim to better describe the distribution of wealth as the polynomial model by Oltean \& Kusmartsev (2014). Also models from statistical physics which describe the process of money creation, exchange and distribution of wealth are used. These models made from statistical physics are gas models without savings, savings and uneven savings. Based on the well-known laws of thermodynamics these models describe economic processes of distribution. Some of the authors who have dealt with the development of these models are Yakovenko V. (2008), Dragulescu (2002) and Chakrabarti \& Chatterjee (2003).

As we have seen, economists and physicists are mainly engaged in the issue of distribution of money, wealth and income to the level of a particular community, such as a country's population. A small number of papers deals with the application of the model distribution of wealth at the global level, but where countries are taken as individual entities. This problem was dealt with by Dunford et al. (2014), and also by Skipper R. (2011). In their they have successfully applied the Pareto distribution model which showed that at the global level there is also uneven distribution of wealth, where GDP is taken as a measure of wealth of a particular country. Also in paper Dunford et al. (2014) analyzed whether Pareto's 80-20 rule applies, where it is determined that the rule applied in 1989, while in the later period it is not confirmed.

The aim of this paper is to analyze the changes in disparities in the distribution of GDP at the global level by using Gini coefficient and checking whether the Pareto's 8020 rule applies or a new rule can be found to this type of distribution. In the second part of paper the goal is to see if Boltzmann Gibbs distribution can be applied for the analysis of distribution of GDP worldwide.

\section{DistRIBUTION MODELS}

In economics Lorenz curve is often used to study the distribution of wealth, income or assets. This model was developed by Max Lorenz in 1905 to present the inequality of wealth distribution. In addition to this problem, this model is used to study the disparities in the size of plants in ecology and biodiversity studies.

Together with the Lorenz curve, the Gini coefficient is used. The Gini coefficient was developed by the Italian statistician Corrado Gini and published in his paper "Variability and mutability". Its value represents the percentage of the area between the line of perfect uniformity of distribution and the observed Lorenz curve in the area between the two extreme positions of the Lorenz curve. This indicator is now often used as a measure of inequality in the distribution. The value ranges between 0 and 1 . Higher values for the Gini 
coefficient indicates uneven distribution, while Gini $=1$ means full uneven distribution (Cvetanović, 2005, p. 94-95). In order to get the true Pareto Principle "80-20", the value of the Gini coefficient should be around 0.76 (Dunford et al., 2014, p. 143).

Vilfredo Pareto discovered in 1879 that the high levels of wealth (but also income) distribution is done according to the law degree distribution. Distribution parameters can be changed from one society to another, but regardless of the social and political conditions Pareto found that the distribution of wealth respects the general law of distribution, which is known as Pareto's law. If $\mathrm{N}$ is the number of people who have the wealth (money) exceeds the amount $\mathrm{x}$, and $\mathrm{A}$ and $\alpha$ are constants, then $\mathrm{N}=\mathrm{A} / \mathrm{x}^{\alpha}$ respectively,

$$
\log (N)=\log (A)-\alpha \log (x)
$$

In other words, the amount of logarithmic number of people with wealth above a certain limit on the logarithmic graph is a straight line. The coefficient $\alpha$ is determined by the slope and the right and is called the Pareto exponent which determines the degree of uniformity of the distribution of resources in the observed population (Dunford Ret al., 2014, p. 141). General Pareto distribution is given by the following probability density function:

$$
P(W)=c W^{-(1+\alpha)}, \text { for } W \geq W_{0} \text { for } W \geq W_{o}
$$

where $W$ is a wealth, $P(W)$ is a function of density, $W_{o}$ is the lower limit of the level of richness and $C$ is a constant and $\alpha$ is known as the Pareto-exponent (Levy \& Solomon, 1997, p. 90).

A number of researchers proved that the model is excellent with the empirical data (Class. et al., 2006), but with certain corrections of the model itself (Clementi \& Gallegati, 2005, p. 3). In the last few years a lot of papers point out that Pareto model is not ideal for the description of the overall distribution of wealth, but describes perfectly only the lower part of distribution, i.e. the distribution between the richest of society (about 3 to 5\%), while in the poorer part which relates to the problem of divergence, which is described by Boltzmann Gibbs distribution (Dragulescu, 2002, p. 10).

This model of distribution has an important use as an indicator of the degree of inequality in the society in the distribution of the fluctuations in the stock markets (Levy \& Solomon, 1997, p. 90).

Pareto originally developed the model to describe the distribution of wealth among individuals, since it seemed that most of the wealth of the society is in the possession of a small number of the members of the same community. It is known as Pareto principle "80-20", which says that $20 \%$ of the population controls $80 \%$ of the wealth of the community. When the value of the Pareto exponent is equal to 1.16 , this means that in the observed population there is the "80-20" principle (Dunford et al., 2014, p. 142).

Many authors confirmed that the probability distribution and the cumulative probability of agent-based models can be described by Boltzmann Gibbs distribution in physics. A fundamental law of equilibrium in statistical physics is the Boltzmann Gibbs law, which states that the probability of $\mathrm{P}(\varepsilon)$ in order to find the physical system or subsystem in a state of energy $\varepsilon$ is determined by an exponential function: 


$$
P(\varepsilon)=c e^{-\frac{\varepsilon}{T}}
$$

In the equation $c$ is the constant of normalization, and $T$ is a temperature which is equal to the average energy per particle. The probability value may range to 1 . In order equations described function in the system must apply the law of the conservation of energy, i.e. that is the summation of the energy that each particle has the same total sum of energy of the system that is constant and that the probability of the particles having energy equal to the sum of energy of two particles is equal to the probability that the product particles have a particle from that particular energy.

Dragulescu and Yakovenko (2001) used Boltzmann Gibbs distribution to describe the distribution of money between agents:

$$
P(m)=c e^{-\frac{m}{T}}
$$

where $m$ is the amount of money that each agent has, and $T$ is the "money temperature" that is equal to the average value of money which each agent has (Yakovenko, 2010). Dragulescu and Yakovlenko (2001) have shown that this model can be applied to describe the distribution of money and income on the example of the US and the UK. Based on the performance of the distribution function, it is obtained that the normalization constant is equal to the reciprocal value of "money temperature".

For the purposes of this study we will use the Gini coefficient for the analysis of uneven distribution for the period 1990 - 2015, while we apply Pareto's model and Boltzmann Gibbs model for 2015.

\section{ANALYSIS OF THE EXISTENCE OF PARETO PRINCIPLE AT THE GLOBAL LEVEL}

In the analysis we used the statistical data for GDP from United Nations, and we looked at the value of GDP in US dollars. The reporting period was from 1990 to 2015 for which data are available. The sample consists of 208 countries that existed in 2015 and the analysis was done for those 208 countries. The analysis was performed in the program Gretl.

Based on the values gained from the analysis that are seen in Figure 1 we can see that the value of the Gini coefficient in the period from 1990 to 1994 is moving upwards, indicating the increase of disparities in the distribution worldwide. This is the period of the disintegration of the USSR, Czechoslovakia and Yugoslavia, which has changed completely the distribution of power at the global level and the period of domination of the West and the USA lasted until 2002 when the Gini coefficient reached its maximum value. After that period, the distribution of power changes, as among the world's economies Asian tigers country are emerging, Russia is recovering from the period of the USSR disintegration and China is becoming more powerful. Also this is the period when BRICS slowly strengthen on the world economic scene, which leads to a drop in the value of the Gini coefficient which reaches its minimum value in 2013.

Also since 2008, the economic crisis has contributed to increasing the uniformity of distribution, but the Gini coefficient rises again in the period after 2013. Figure 2 shows the Lorenz curve for 2015. 


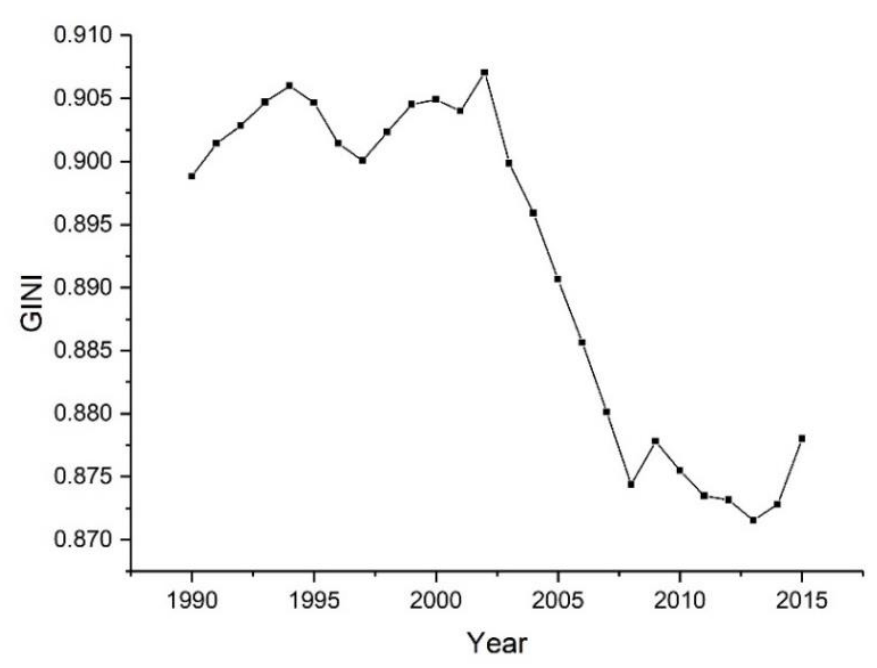

Fig. 1 Value of the Gini coefficient for the period 1990 - 2015

Source: Data processed by the author

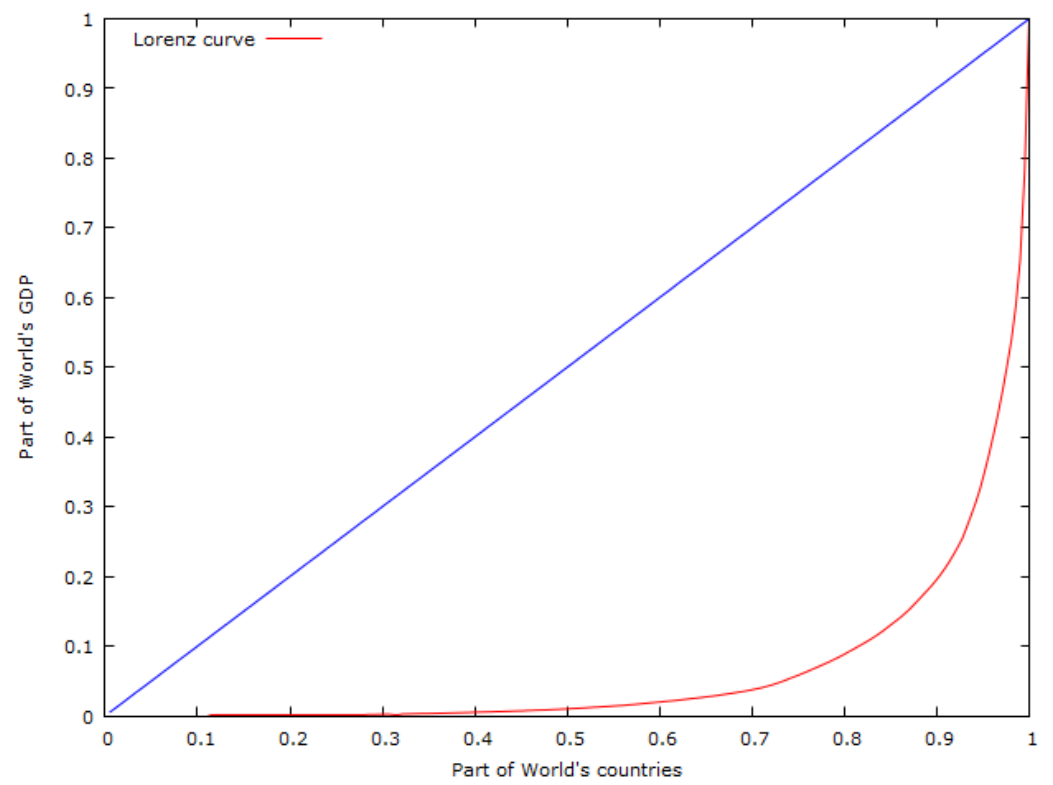

Fig. 2 Lorenz curve for 2015

Source: Data processed by the author 
The value of the Gini coefficient shows a high degree of uneven distribution of the value of GDP at the global level, which is certainly caused by a number of factors: population, natural resources, the size of the territory, the technological development of the country, the structure of the economy, the education system and so on.

Based on the obtained value of the Gini coefficient when it comes to the distribution of GDP Pareto Principle does not apply because the Gini coefficient is much greater than the value necessary for the "80-20" rule, i.e. 0.76 . It is better to say that for this distribution we can apply the "90-20" rule. This conclusion can be drawn from the values shown in Figure 3 which shows the relationship between the value of the richness of individual groups of countries.

Based on the values from Figure 3 in the initial period, the share of the richest $20 \%$ went up to nearly $95 \%$ of the total wealth, while in 2015 this amount was reduced to a little over $91 \%$, which thus proves that when we talk about the distribution of GDP at the global level, the Pareto rule does not apply. Also it is important to note that here we took into account distribution between countries rather than among the population, as in all countries, there are small groups that are extremely wealthy compared to the rest, so for future research it would be interesting to try to determine whether the Pareto Principle applies in the distribution of wealth (income, money, etc.) at the level of individual countries or countries of the world.

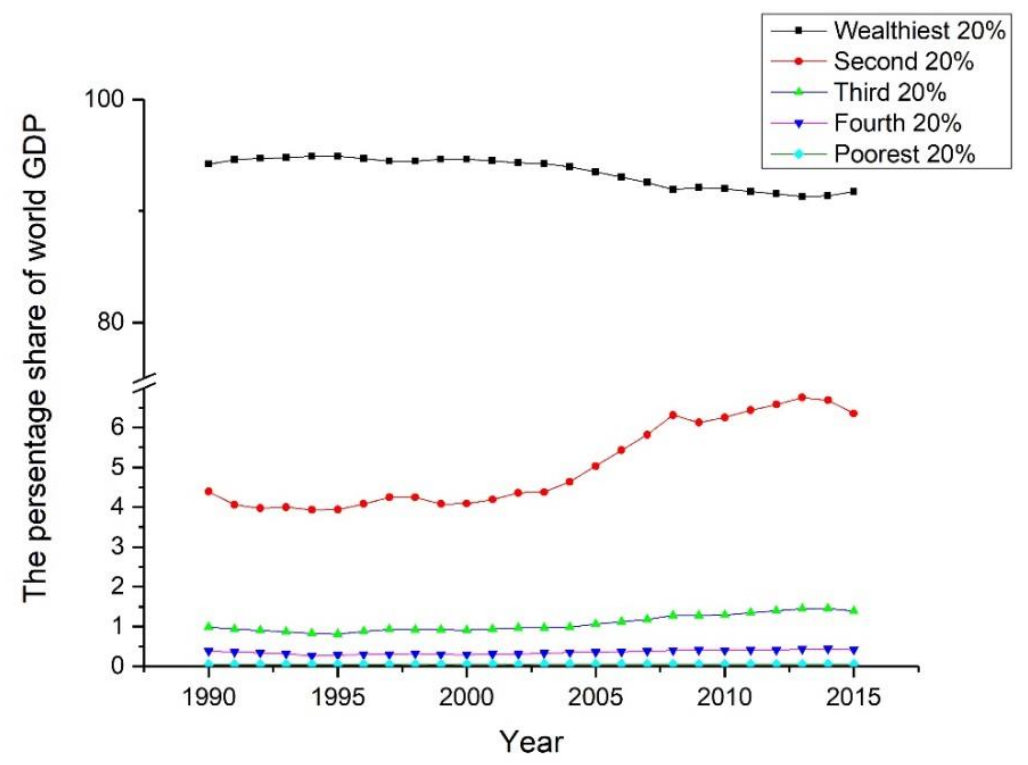

Fig. 3 Percent share in the global GDP per year Source: Data processed by the author 


\section{Pareto and Boltzmann GibBs Distribution of GDP at the Global LeVEL}

Testing the Pareto distribution will start by using the equation (1) where we will determine whether we can apply the Pareto distribution to determine the distribution of GDP of countries on the basis of their rank. The analysis was carried out in the Origin program and the results were as follows.

Based on the analysis in Origin and from Figure 4, we can see that the Pareto distribution function best describes the initial part of the distribution, i.e. distribution of GDP between the richest countries (the richest 42 countries, i.e. the richest 20\%). This version of the Pareto distribution, Zipf's function can describe the distribution of wealth (GDP, money,...) only for the richest. The rest of the countries in the graph we see that it does not provide the best description of distribution, i.e. it is a country that ranked lower theoretical value different from the empirical value that is recorded. This finding was confirmed in the work of Skipper (2011) that this form of Pareto distribution can best describe just distribution of the world's richest countries. Also, many authors have tested the Pareto distribution and found that in the case of the distribution of wealth among individuals, the Pareto model is best to describe the 3-5\% of the richest members of the population, while other models describe the rest of the mode of distribution, such as in the papers of Dragulescu and Yakovenko (2001).

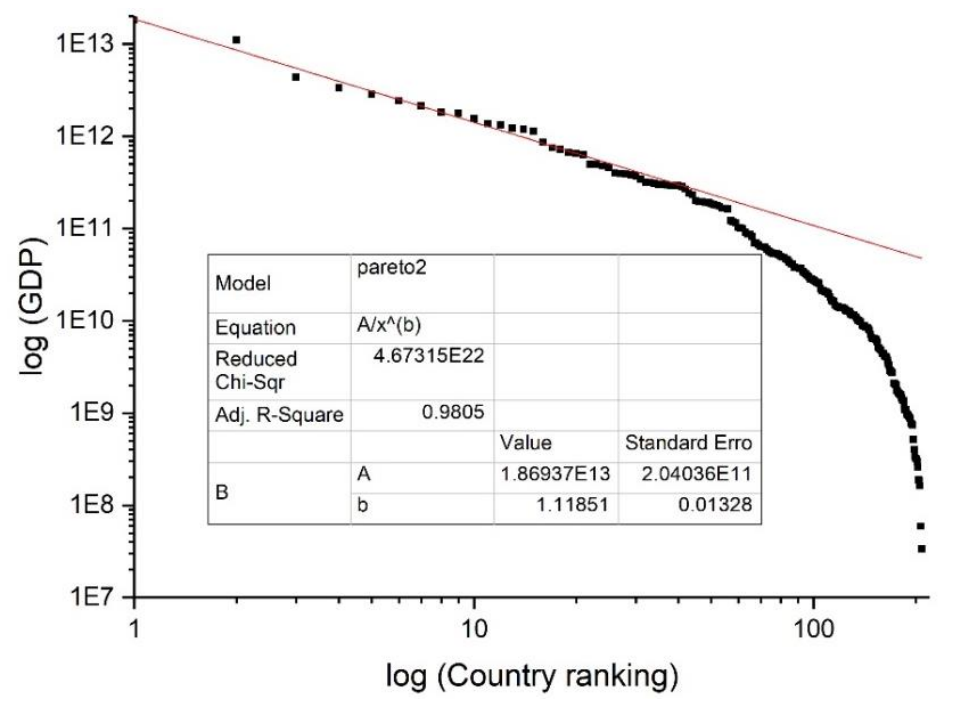

Fig. 4 Pareto distribution Source: Data processed by the author

The following will apply the general Pareto distribution and Boltzmann Gibbs distribution to determine its applicability. 


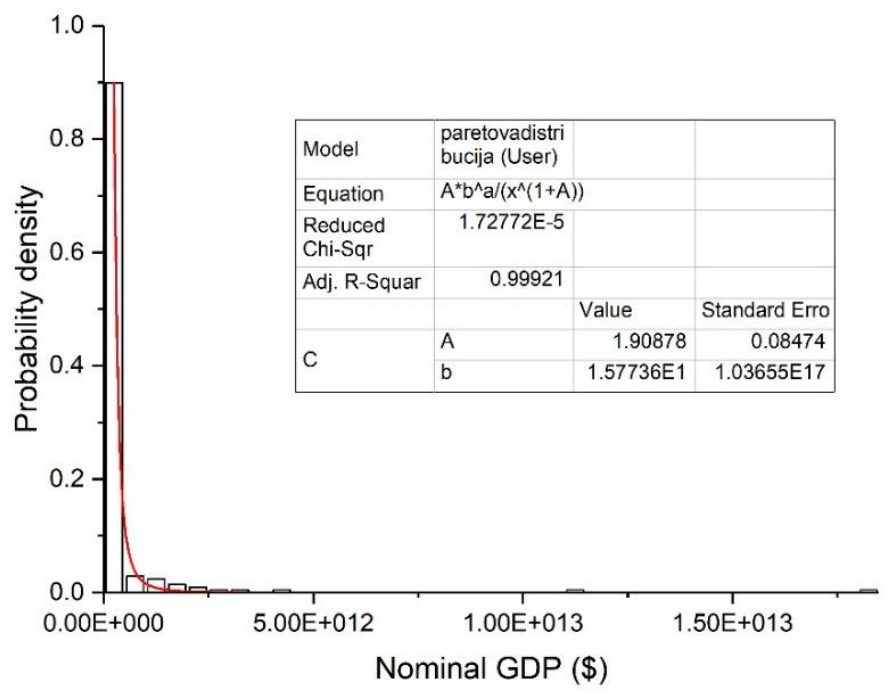

Fig. 5 Pareto distribution of nominal GDP Source: Data processed by the author

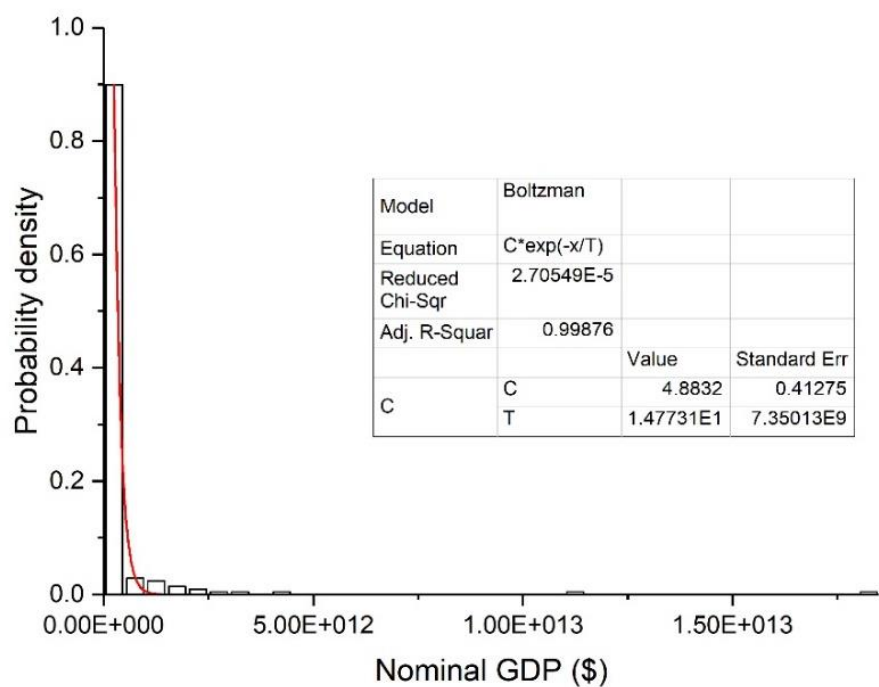

Fig. 6 Boltzmann Gibbs distribution of nominal GDP Source: Data processed by the author

Based on Figure 5, we can see that the Pareto distribution describes well the distribution of GDP at world level. Our analysis took into account the 208 countries which are divided into groups depending on the value of their GDP. The coefficient of determination is very 
high which shows that this model a $99.9 \%$ change in the value of the parameter described by this model. On the same data, we applied Boltzmann Gibbs model which is given by the equation (5) and the obtained results are shown in Figure 6. The Boltzmann Gibbs model describes well the distribution of GDP. The coefficient of determination in this case is somewhat lower than for the Pareto model.

We can conclude that both models describe well the distribution of world GDP countries. These models describe individual distribution made, not cumulative. Regarding the cumulative distribution, it is shown that the Pareto distribution model best describes the observed distribution of the richest part of the population, while the Boltzmann Gibbs model best describes the distribution of the rest. We will test the data for the distribution of world GDP which can be seen in Figure 7.

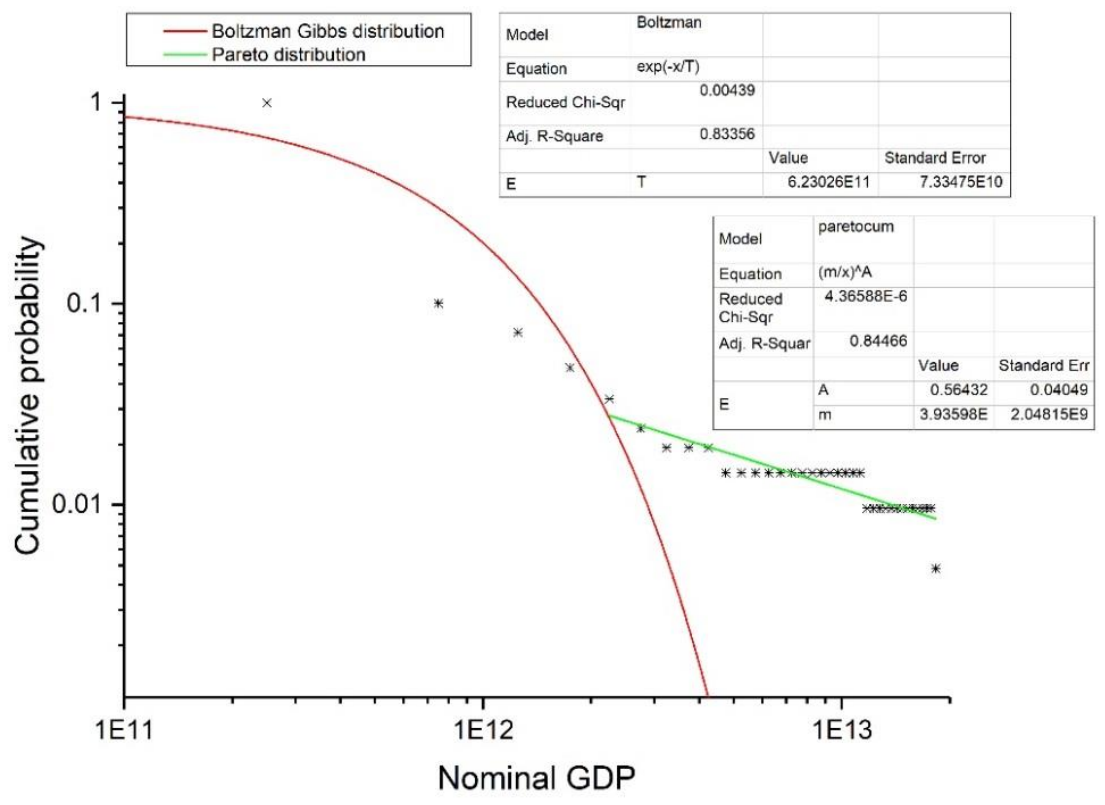

Fig. 7 The cumulative probability distribution Source: Data processed by the author

Based on the analysis we can see that the combination of the Boltzmann and Gibbs and Pareto distribution perfectly describes the distribution of GDP at world level. We confirmed what Drăgulescu and Yakovenko (2001) stated in their work using this data. Specifically, the Pareto function describes the part that refers to the richest countries, while the poorest countries are best described by the Boltzmann Gibbs function. The information in the case of 208 countries are processed in groups of countries, depending on the value of the country's GDP. Based on the data we can conclude that the Pareto model perfectly describes the cumulative distribution relating to the distribution of wealth by $2.4 \%$ of the richest countries in the world, while the Boltzmann Gibbs distribution describes the distribution of the rest of the countries, which is another confirmation of the conclusions reached in the research by Dragulescu and Yakovenko (2001). 


\section{CONCLUSION}

The problem of the distribution of money and wealth attracted the attention of many researchers. In addition to the Pareto model, which is most commonly used, there are other models that have been designed by econophysicists, like the Boltzmann Gibbs model from statistical physics.

In this paper we first analyzed the existence of Pareto's rule "80-20". We did not confirm the existence of this rule for the distribution of world GDP. In this paper we found that rule "90-20", i.e. $90 \%$ of the world GDP is created by $20 \%$ of the richest countries in the world (42 countries in total), exists and can be used as the Pareto rule when it comes to distribution of the world GDP. In future research, we can try to see if the new form of Pareto "80-20" exists, i.e. $80 \%$ of the world GDP is owned by 20 richest countries.

Secondly, in this paper we tested the Boltzmann Gibbs model of distribution to describe the distribution of GDP among countries worldwide. Using a sample of 208 countries, we found that the Boltzmann Gibbs distribution can be applied to describe the distribution of a number of the poorest countries, while the Pareto model can be applied to describe the distribution between the richest countries.

This finding confirms the research of Dragulescu and Yakovenko (2001) as well as other authors. They did theirs research on the examples of the problems of distribution of wealth among individuals. In a study in 2015, we showed that the Pareto distribution model describes the cumulative GDP of $2.4 \%$ of the world's countries, while the rest is described by the Boltzmann Gibbs distribution.

Further studies can test the application of other models, such as the Gamma function, to describe the distribution of GDP, as well as work on theoretical grounds for the applicability of the model to describe the distribution.

\section{REFERENCES}

Clementi, F. \& Gallegati, M. (2005). Pareto's Law of Income Distribution: Evidence for Germany, the United Kingdom, and the United States. In: Chatterjee A., Yarlagadda S., Chakrabarti B.K. (eds) Econophysics of Wealth Distribution (pp.3-14). New York: Springer.

Chakrabarti, B. \& Chatterjee, A. (2003). Ideal Gas-Like Distributions in Economics: Effects of Saving Propensity. In: Takayasu H. (eds) The Application of Econophysics (pp.280-285). Tokyo: Springer.

Cvetanović, S. (2005). Teorija privrednog razvoja [Theory of economic development]. Niš: Ekonomski fakultet u Nišu.

Dragulescu, A. \& Yakovenko, V. (2001). Exponential and power-law probability distributions of wealth and income in the United Kingdom and the United States. Physica A, 299 (1-2), 213-221.

Dragulescu, A. (2002). Applications of physics to economics and finance: Money, income, wealth, and the stock market, Dissertation Abstracts International, Volume: 64-01, Section: B, page: 0245.; 94 p (https://arxiv.org/pdf/cond-mat/0307341v2.pdf)

Dunford, R., Su Q., Tamang E. \& Wintour A. (2014). The Pareto Principle. The Plymouth Student Scientist, 7 (1), 140-148

Kitanović, D. \& Golubović, N. (2006). Osnovi ekonomije [Basic of Economics]. Niš: Ekonomski fakultet u Nišu.

Klass, O., Biham, O., Levy, M., Malcai, O. \& Solomon, S. (2006). The Forbes 400 and the Pareto wealth distribution. Economics Letters, 90, 290 - 295.

Levy, M. \& Solomon, S. (1997). New evidence for the power-law distribution of wealth. Physica A, 242 (1-2), 90-94.

Oltean, E. \& Kusmartsev, F. (2014). An Econophysical Approach of Polynomial Distribution Applied to Income and Expenditure. American Journal of Modern Physics, 3 (2), 88-92.

Sinha, S. (2006). Evidence for Power-law tail of the wealth distribution in India. Physica A, 359 (1), 555-562. 
Skipper, R. (2011). Zipf 's Law and Its Correlation to the GDP of Nations. The University of Maryland McNair Scholars Undergraduate Research Journal, 3, 2011, 217-226.

Yakovenko, V. (2008). Econophysics, Statistical Mechanics Approach to. In: Encyclopedia of Complexity and System Science (pp.2800-2826). New York: Springer.

Yakovenko, V. (2010). Statistical Mechanics of Money, Debt and Energy Consumtion. Science and Culture, 76 (9-10), 430-436.

Statistical base of UN, http://unstats.un.org/unsd/snaama/dnltransfer.asp?fID=2, accessed 31.08.2017.

\section{MODELI DISTRIBUCIJE BDP NA SVETSKOM NIVOU}

Problem distribucije okuplja pažnju istraživača godinama unazad. U svojim istraživanjima se bave analizom ravnomernosti raspodele primenom modela Paretove distribucije, Lorencove krive $i$ Gini koeficijenta. Postoje i radovi gde se testiraju primenljivost modela iz statističke fizike kako bi se problem distribucije što bolje opisao. Pored analize distribucije na nivou država i određenih grupa poput Forbsove liste, problem se širi na svetski nivou gde se analizira distribucija BDPa kao mere bogatstva pojedinih zemalja.

$U$ ovom radu analizirali smo distribuciju BDPa zemalja primenom Paretovog modela, Lorencove krive, Gini koeficijenta i Bolcman Gibsove raspodele iz statističke fizike. Izvršena je analiza za 2015. godinu, dok je na osnovu Gini koeficijenta izvršena analiza dinamike promene ravnomernosti distribucije u periodu od 1990. do 2015. godine.

Ključne reči: Distribucija bogatstva, BDP, Paretova distribucija, Lorencova kriva, Gini koeficijent, Bolcman Gibsova raspodela 